\title{
Bioassay-guided Identification of the Nematicidal Secondary Metabolites from Paecilomyces lilicanus for the Control of Root-knot Nematode (Meloidogyne graminicola, Golden and Birchfield)
}

\author{
Ruben M. Gapasin ${ }^{1}$, Erlinda A. Vasquez ${ }^{2}$ and Giselle A. Rendon ${ }^{3}$ \\ ${ }^{1}$ Department of Pest Management, Visayas State University (VSU), ViSCA, Baybay, \\ Leyte; ${ }^{2}$ PhilRootcrops, VSU, ViSCA, Baybay, Leyte; ${ }^{3}$ PhilRice, Agusan
}

\begin{abstract}
Meloidogyne graminicola larvae immersed for 48 hours in $100 \%$ concentration of Paecilomyces lilacinus culture filtrate had $100 \%$ larval mortality while only $7.12 \%$ and $18.72 \%$ mortality was recorded, after 6 and 12 hours immersion, respectively. Toxic metabolites present in the culture filtrate affected the larvae as there were no galls produced in rice seedlings at $100 \%$ concentration. The culture filtrate also limited egg hatching as shown by lesser galls produced in rice seedling roots. The mycelial extract was found more potent compared with the culture filtrate extract; however, both fractions affected the larvae and eggs of M. graminicola.

The dried ethyl acetate fraction gave $88.51 \%$ mortality at concentration of 500 $\mathrm{mg} / \mathrm{ml}$, followed by $76.91 \%$ at concentration of $400 \mathrm{mg} / \mathrm{ml}$. A lethal concentration (LC) of $50 \%$ was attained at $300 \mathrm{mg} / \mathrm{ml}$. Sixteen fractions were recovered from the crude dried extract of the fungus using vacuum liquid chromatography (VLC). Bioassay revealed that fraction 3 (combined fractions 5, 6 and 7) gave 39 percent nematode mortality suggesting that the nematoxic compounds are present in these fractions.

The fragmentation pattern in GC-MS revealed that the active fraction contains more than 20 compounds with 5 major ones. The structure of the main compound was partially identified as derivative of azulene containing two unsaturation points. The limited amount of the fraction subjected to spectroscopic analysis does not warrant its purification to be able to do other analysis such as NMR spectroscopy for structure elucidation and complete compound identification.
\end{abstract}

Keywords: nematicidal, metabolites, nematophagous, Paecilomyces lilacinus, rootknot nematode, Meloidogyne graminicola, culture filtrate, azulene

Correspondence: RMGapasin Address: Department of Pest Management, Visayas State University, Baybay City, Leyte 6521-A Philippines Email: rmgapasin1952@yahoo.com DOI: 10.32945/atr3322.2011 


\section{INTRODUCTION}

Root-knot nematodes (Meloidogyne spp.) are worldwide in their distribution and crop losses are estimated to reach about 13\% (Sasser, 1979). Infected plants show reduced growth, swollen roots which develop into the typical root-knot galls, are two, or three times larger in diameter as healthy root. Root-knot nematodes are very difficult to control because they are polyphagous; the life cycle is almost completely confined inside the host plant and high reproductive capacity. Although chemical control is still a common method for reducing nematode population, there is a considerable public pressure to limit or even ban the use of nematicides. Many nematicides are highly toxic and sometimes very mobile in the soil because of their solubility in water. Concern over these chemicals has led to an increased interest in biological control in order to achieve more environmentally friendly methods of reducing nematode damage.

The fungal antagonist of nematodes consist of a great variety of organisms which include the nematode-trapping or predaceous fungi, endoparasitic fungi, parasites of nematode eggs, parasites of nematode cyst and fungi which produce toxic metabolites that kill nematodes (Mankau, 1980). Paecilomyces lilacinus is one of the many fungi most frequently encountered and is found effective in reducing nematodes in the soil. Their destructive activity includes hyphal colonization and enzymatic disruption of nematode structural elements such as eggshells and larval cuticles, and physiological disturbances brought about by biosynthesis of diffusible toxic metabolites (Morgan-Jones and RodriguezKabana, 1985). In a recent undertaking, P. lilacinus culture filtrate incubated for 30 days gave a $100 \%$ larval mortality at 50 percent concentration (dela Piza, 2003). However, there was no attempt to identify the nematicidal compound in the culture filtrate.

The ultimate aim of this study is to identify the compounds/ metabolites present in P. lilacinus, a fungal biological control agent of plant parasitic nematodes, which could be used to reduce nematode infection in economically important crop plants thereby increasing their yield. Another possible output is the development of agricultural products for pest control. The compounds isolated which have either suppressive 
or deterrent properties against pest particularly nematodes could be utilized as pesticide or as templates in the development of more potent activity with reduced toxicity and non-persistent agric-products. This means that we will be developing an environment friendly pesticide.

\section{MATERIALS AND METHODS}

\section{Culture of Paecilomyces lilacinus in Liquid Media}

Pure culture of $P$. lilacinus acquired from the collections of the Department of Pest Management was sub-cultured in potato dextrose agar (PDA) medium and then incubated at room temperature. An oatmeal liquid medium (oatmeal, 75g; distilled water, 1 liter) was prepared, placed in $500 \mathrm{ml}$ flasks, and sterilized for one hour at 15 psi. Previously grown P. lilacinus was inoculated to the liquid media aseptically and incubated under room temperature for 60 days.

Mass-Culture of Meloidogyne graminicola in Rice (UPLRi-5)

Pure culture of the nematode was mass-produced by inoculating 1,000 larvae of the nematode to susceptible UPLRi-5 rice grown in sterilized soil. Inoculated plants were maintained outside the screen house for 60 days.

\section{Preparation of P. lilacinus Culture Filtrate}

The culture filtrate of $P$. lilacinus from each flask was removed using a pipettor. Culture filtrate was filtered using sterilized filter paper and funnel, placed in sterilized flask. The filtrate was placed in the refrigerator until ready for use in the succeeding bioassay. 


\section{Extraction of Culture Filtrate}

One-liter culture filtrate was mixed with ethyl acetate in separator funnel and shaken for 3 minutes. The aqueous (water) and ethyl acetate fractions were transferred separately to a beaker and concentrated using rotary evaporator (Rotavap R110) at $30-40^{\circ} \mathrm{C}$. The concentrated fractions were placed in vials and refrigerated for use in the succeeding bioassay.

\section{Preparation and Extraction of P. lilacinus Mycelia}

The mycelia of the fungus from each flask were collected using sterilized forceps and weighed using the triple beam balance. A known volume $(500 \mathrm{ml})$ of sterile water was added into the mycelial mat, and was osterized for 3 minutes. One liter of methanol (as solvent) was added to the mixture and transferred into the separatory funnel. The aqueous and methanol fractions of the mycelia was transferred separately and filtered using a vacuum pump and the fractions were placed in sterilized beaker. The methanol and aqueous fraction were concentrated using the rotary evaporator (Rotavap R110) at $30-40^{\circ} \mathrm{C}$. The concentrated fractions were placed in vials and refrigerated until ready for use in the succeeding bioassay.

\section{In Vitro Bioassay of P. lilacinus Culture Filtrate}

Bioassay of the culture filtrate against $M$. graminicola larvae was carried out using the immersion test. This was done by immersing approximately 75 freshly hatched larvae (contained in $0.1 \mathrm{ml}$ nematode suspension) to $2 \mathrm{ml}$ culture filtrate placed in plastic plates at different concentrations of $100 \%, 50 \%, 40 \%, 30 \%, 20 \%, 0 \%$ (sterile distilled water only). Dead and alive nematodes were counted at 3,6,12, 24, and 48 hours under a stereomicroscope with the aid of a multiple tally counter. Erect and non-moving nematodes were counted as dead. The effect of the culture filtrate on $M$. graminicola eggs were assayed following the same procedure as in the bioassay for larvae but eggs were incubated only for 48 hours and later inoculated to previously rooted rice seedlings. 
The different treatments were replicated 4 times and arranged in Completely Randomized Design (CRD) in the Laboratory. Differences in the means were compared using the Duncan's Multiple Range Test (DMRT).

\section{In vitro Bioassay of the Different Fractions of Culture Filtrate and Mycelia Extract}

The aqueous and ethyl acetate fractions of the culture filtrate and the aqueous and methanol extracts of the mycelia were assayed using approximately 60 nematode larvae following the same procedure as in the culture filtrate bioassay. From the concentrated fractions (stock solution) different concentrations ( $300 \mathrm{ppm}, 500 \mathrm{ppm}, 800 \mathrm{ppm}$ and 1,000 $\mathrm{ppm}$ ) were prepared which were designated as the treatments with 4 replications. A 3\% ethyl acetate and 3\% methanol were prepared as negative control and the distilled water as the positive control. Dead and alive larvae were counted under the stereomicroscope with the aid of a tally counter after 3, 6, 12 and 24 hours.

Since the stock solution from the concentrated culture filtrate and mycelia were different, the stock solution from the culture filtrate was adjusted by adding sterile water. Different concentrations of $100 \%, 50 \%$, $25 \%, 10 \%$, and $0 \%$ (distilled water) were then prepared. A solution of $0.2 \mathrm{ml}$ was placed to each plastic plate and approximately 60 larvae and eggs were added. The different treatments with 4 replications were incubated for 24 hours, arranged in CRD in the Laboratory. Differences in the means were compared using DMRT. Dead and alive nematode larvae were counted under the stereomicroscope with the aid of a hand tally counter every 3 hours until the $24^{\text {th }}$ hour. Percent mortality was computed.

\section{Confirmation of Nematode Mortality}

The mortality of the nematode was further confirmed by inoculating the nematode-containing filtrate and mycelial extract (treatments corresponding with the in vitro bioassay) into two week-old rice seedlings 
planted in plastic pots. After 21 days, the rice plants were uprooted and washed of soil debris and examined for the presence of galls and then counted. The presence of galls in roots would indicate that the immersed larvae were still alive and thus, were not affected by the filtrate or extract.

\section{Extraction and Fractionation of the Active Compounds}

Culture filtrate of $P$. lilacinus incubated for 60 days in oatmeal liquid culture medium was taken and filtered through a Buchner funnel with gentle suction. The filtrate was extracted using ethyl acetate. The extraction with ethyl acetate was repeated three to four times. The ethyl acetate fraction was then concentrated in vacou using a rotary evaporator. The extract was evaluated for nematicidal activity through assay as previously described.

The dried ethyl acetate extract was then subjected to vacuum liquid chromatography (VLC) using the following solvent system; 1:1 ethyl acetate-hexane followed by $100 \%$ acetone; $2 \%$ methanol in acetone, $4 \%$ methanol in acetone, $6 \%$ methanol in acetone and $10 \%$ methanol in acetone. The extracts were collected in separate containers, and concentrated in vacou using a rotary evaporator. The extracts were evaluated against the nematode larvae through a bioassay.

Analysis and identification of compounds in the active fraction of Paecilomyces lilacinus

The active fraction of the ethyl acetate extract of $P$. lilacinus was analyzed by gas chromatography and gas chromatography-mass spectrometry on a Finnigan Polaris Q GC/MS Ion Mass Spectrometer using a BPX5 capillary column ( $30 \mathrm{~m} \times 0.32 \mathrm{~mm}$ ID, $0.25 \mathrm{~mm}$ film). Using helium as carrier gas the column was operated with temperature programmed from $50^{\circ} \mathrm{C}$ for 5 minutes and raised to $280^{\circ} \mathrm{C}$ at $10^{\circ} \mathrm{C} / \mathrm{min}$. with 15 minutes holding time and raised again to $300^{\circ} \mathrm{C}$ at $10^{\circ} \mathrm{C} / \mathrm{min}$ and holding time of $10 \mathrm{~min}$. Three injections of $0.5 \mathrm{ml}$ from $10 \mathrm{ml}$ concentrated active fraction were done. 
Compounds in the fraction were identified by comparison with the retention time and mass spectra of synthetic standard analyzed under the same conditions and comparison with NIST library.

\section{RESULTS AND DISCUSSION}

\section{Nematicidal Efficacy of Paecilomyces lilacinus Culture Filtrate}

The percent mortality of larvae immersed at different periods (hours) using different concentrations of 60-day-old P. lilacinus culture filtrate is shown in Figure 1. No mortality was observed after 3 hours immersion of larvae in the culture filtrate, however after 6 hours $7.12 \%$ mortality was recorded at $100 \%$ concentration. This caused more than $50 \%$ mortality after 24 hours, which was significantly different with the rest of the treatments. Then after 48 hours of immersion in $100 \%$ concentration of culture filtrate, there was $100 \%$ mortality while at $50 \%$ and $40 \%$ concentrations, there was $70 \%$ and $50 \%$ mortality, respectively, which were significantly different with each other. The results showed that there

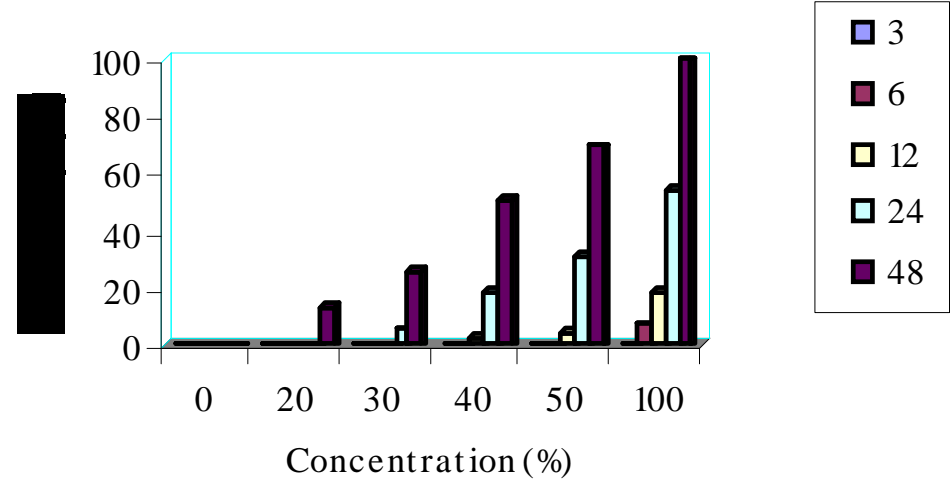

Figure 1. Per cent mor tality of nematode lar vae immer sed in dif fer ent concentrations of Paecilomyces lilacinus culture filtrate at various time dur ation 
was an increased mortality with concentrations and immersion time to the culture filtrate. This was in consonance with the results obtained by Dela Piza (2003). However, she observed $100 \%$ mortality of $M$. incognita even at $50 \%$ concentration of the culture filtrate after 48 hours immersion. This difference in result may be due to the species of nematode used. Apparently, M. graminicola larvae are more resistant or tolerant compared with $M$. incognita since at 48 hours immersion at $50 \%$ concentration of the culture filtrate only $69.46 \%$ mortality was observed.

The paralysis or death of larvae may be attributed to enzyme component of the culture filtrate as reported by Cayrol et al., (1989). In a related report, Park et al., (1988) as cited by Dela Piza (2003) observed protease activity on gelatin medium and chitins activity on colloidal chitin medium of different isolates of P. lilacinus. Ode et al., (1997) observed poly (3-hydroxybutyrate) depolymerase from the fungus $P$. lilacinus D218 by column chromatography.

A plant bioassay test was done to verify whether the larvae and eggs immersed in the culture filtrate at different concentrations after 48 hours were either paralyzed or dead. The number of galls produced in rice seedlings 21 days after inoculation with the immersed larvae in culture filtrate is presented in Figure 2. No galls were observed in the roots of plants inoculated with larvae immersed in the $100 \%$ concentration of the extract indicating that all larvae died after 48 hours. This was significantly different with the rest of the treatments. The results also showed that as the concentration was decreased, the higher is the number of galls produced. This observation was in consonance with that of Cayrol et al., (1989) who found out that toxicity of culture filtrate of P. lilacinus decreased rapidly when filtrate was diluted.

Likewise, the eggs of M. graminicola were affected by the culture filtrate when immersed for 48 hours at different concentrations of the filtrate. At $100 \%$ concentration, the lowest number of galls of 15.00 was observed which was significantly different with the control and the $20 \%$ and $30 \%$ concentrations but was not significantly different with the $40 \%$ and $50 \%$ concentrations. These results showed that the toxic metabolites from the culture filtrate inhibited egg hatching. This affirmed the observations of Park et al., (1998) who reported that egg production of 


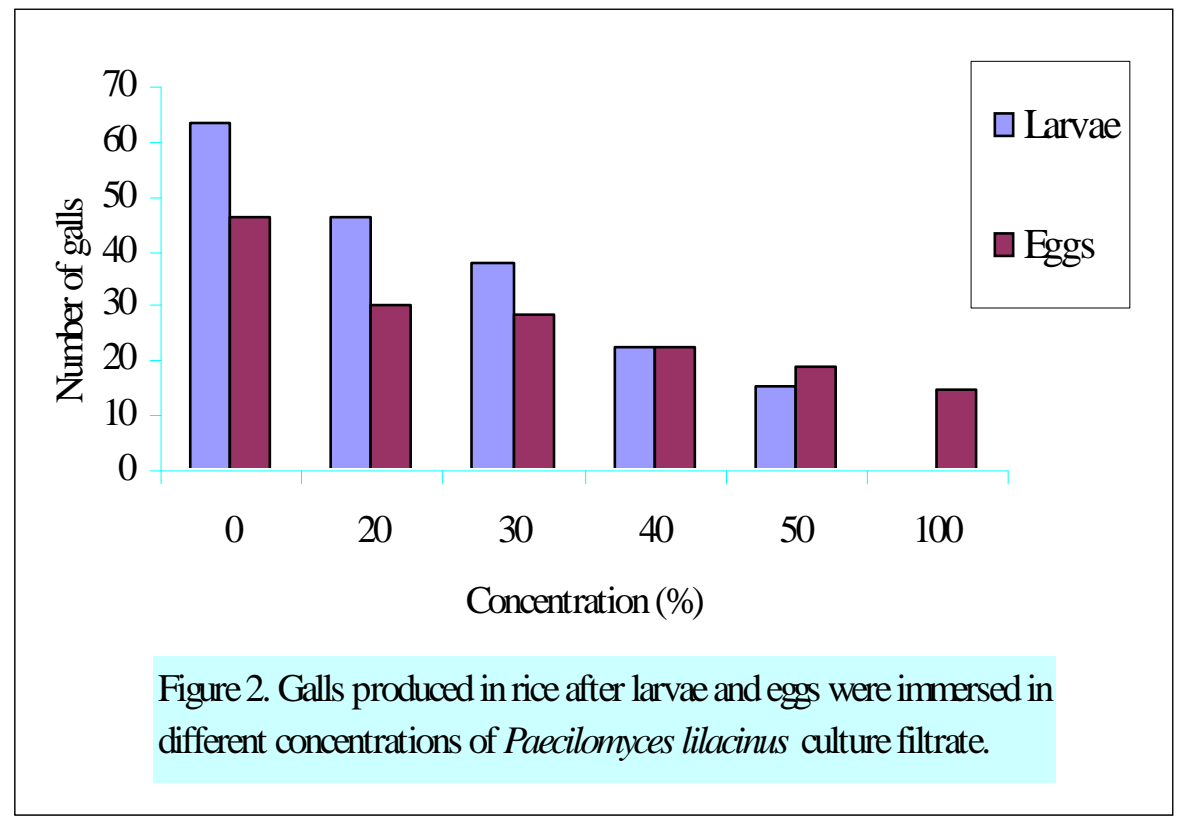

Caenorhabditis elegans was inhibited when exposed to six isolates of $P$. lilacinus for 7 days. Similarly, Dela Piza (2003) also found suppression of egg hatching of $M$. incognita when exposed to P. lilacinus culture filtrate. The eggs' vitaline membrane may also have been disintegrated due to enzyme activity. According to Bonants et al., (1995) serine protease from $P$. lilacinus may play a role in the penetration of the fungus through the eggshell of $M$. hapla.

Efficacy of Aqueous Fractions of P. lilacinus Culture Filtrate and Mycelia Extract

The concentrated aqueous fraction $(414 \mathrm{mg} / 12 \mathrm{ml})$ of the culture filtrate extracted with ethyl acetate showed very high and fast activity against the nematode larvae with more than 50\% mortality after 3 hours immersion (Figure 3). After 6 hours, all the larvae were immobile or dead until the 24 hours observation. This was significantly different with the rest of the treatments. There was very low activity of the fraction at 


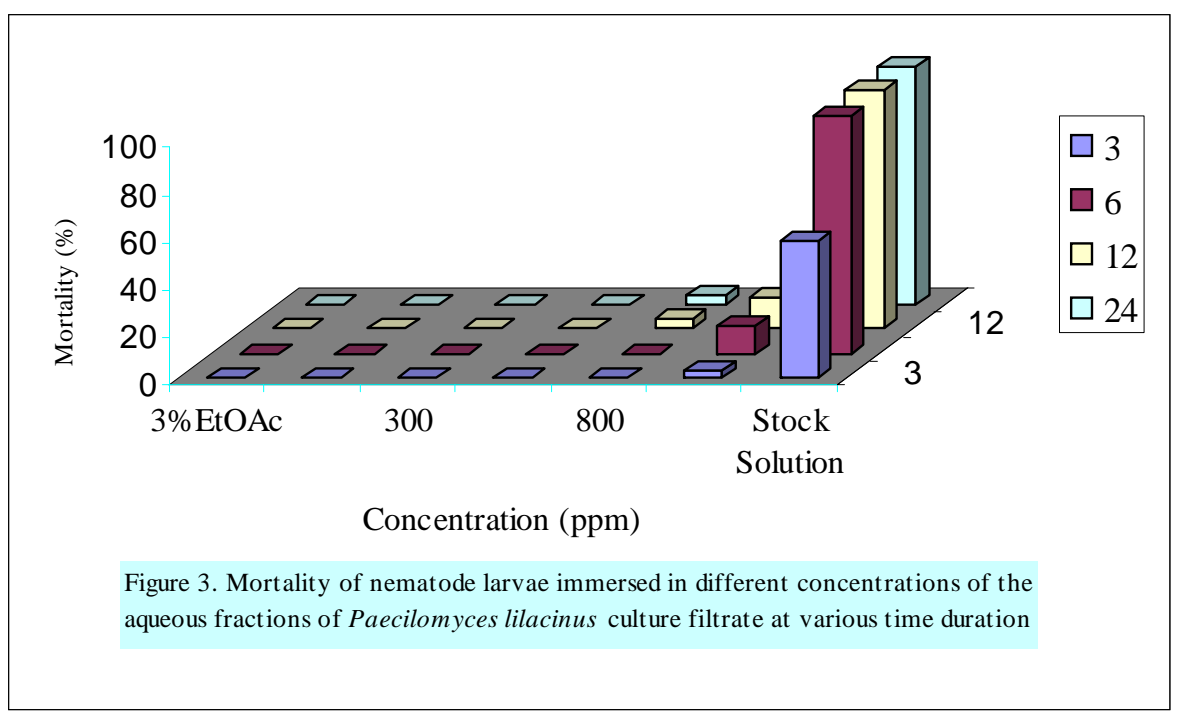

1000 ppm even after 24 hours. As there was no mortality observed in the $3 \%$ ethyl acetate (negative control) that would indicate its toxicity, death of the larvae could be attributed solely to the toxic compound present in the culture filtrate.

The aqueous fraction of the mycelia $(68 \mathrm{mg} / 10 \mathrm{ml})$ when extracted with methanol was also toxic with more than $50 \%$ mortality after 6 hours and attaining $100 \%$ mortality after 24 hours (Figure 4). This was significantly different with the rest of the treatments. At $1000 \mathrm{ppm}, 7.59 \%$ mortality was recorded which also significantly different with the other treatments (300 ppm, 500 ppm, and 800 ppm) which had zero mortality. This could be due to the very low concentration level or the preparations were too diluted that the nematode could tolerate their nematicidal activity. No mortality was recorded in the $3 \%$ methanol, again indicating that larval mortality was due to the toxicity of the mycelia extract and not the methanol.

\section{Comparative Efficacy of Culture Filtrate and Mycelial Extract}

The aqueous fraction of the mycelia was more toxic compared with the aqueous fraction from culture filtrate (Figure 5). There was higher 

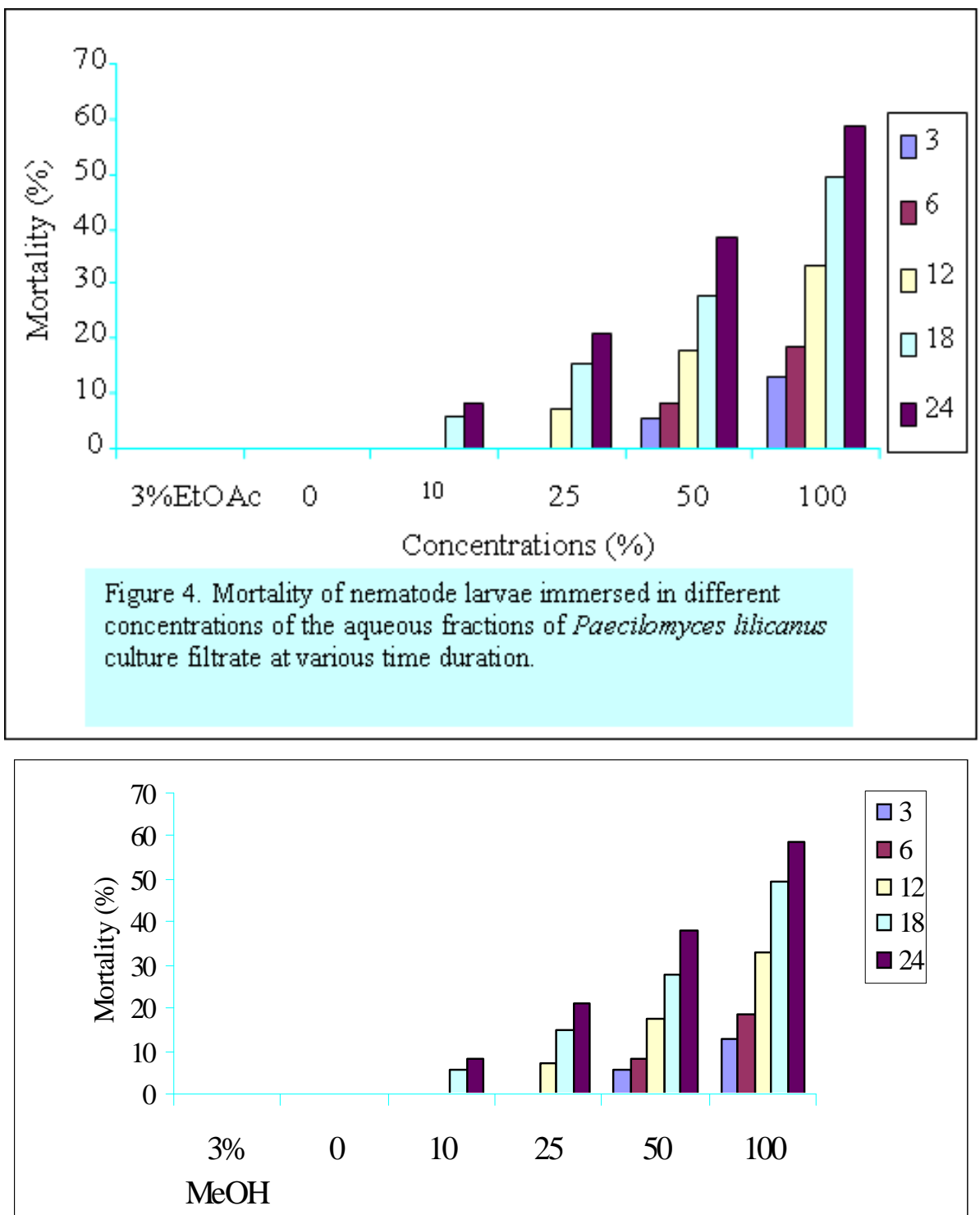

\section{Concentration (\%)}

Figure 5. Mortality of nematode larvae immersed in different concentrtions of the aqueous fractions of Paecilomyces lilacinus mycelial extract at various time duration 
mortality in the mycelia extract regardless of concentration and immersion time. At 6 hours immersion time, more than $50 \%$ mortality was recorded at $100 \%$ concentration in the mycelial extract while only $18.51 \%$ was recorded in the culture filtrate extract. At 24 hours immersion time, $100 \%$ mortality was observed in the mycelia extract at $100 \%$ concentration while only $58.57 \%$ was observed in the culture filtrate.

These results clearly indicate that more toxic compounds were still present in the mycelial extract compared with the culture filtrate extract after 60 days. The medium may have affected maximum toxin production by the fungus. According to Cayrol et al., (1989), the toxic properties of P. lilacinus are greatly influenced by the liquid culture medium. In CzapekDox modified medium, the toxic metabolites were not produced at any dilution while in the Arconteil modified medium, the toxicity was weak in pure culture filtrate. In the two synthetic media (Czapek-Dox and Mac Coy media) the toxicity was greater. While we can get high toxicity using the synthetic media this may be costly and not readily available compared with the medium used in this experiment.

No galls were produced when inoculated with larvae immersed in $100 \%$ concentration of the mycelia extract, indicating that all larvae were dead after 24 hours. However, not all the eggs were affected as 6.25 galls were recorded. This implies that the eggs were resistant due to the vitalline membrane and protein component of the egg shell. Some larvae may have hatched in the soil upon egg inoculation of the immersed egg thereby escaped the effect of toxin thus some galls were observed. Higher number of galls was found in the control and in the $3 \%$ ethyl acetate and $3 \%$ methanol treatments in both culture filtrate and mycelial extracts indicating a very low toxicity in these treatments. Significant differences were observed among the treatments.

\section{Effect of the Different Fractions on Nematode Larvae}

Figure 6 shows the percent mortality of root-knot nematode (RKN) immersed in ethyl acetate (EtOAC) fraction with the highest mortality of $88.51 \%$ at concentration of $500 \mathrm{mg} / \mathrm{ml}$, followed by $76.91 \%$ at concentration of $400 \mathrm{mg} / \mathrm{ml}$. A lethal concentration (LC) of $50 \%$ was attained at $300 \mathrm{mg} / \mathrm{ml}$. 


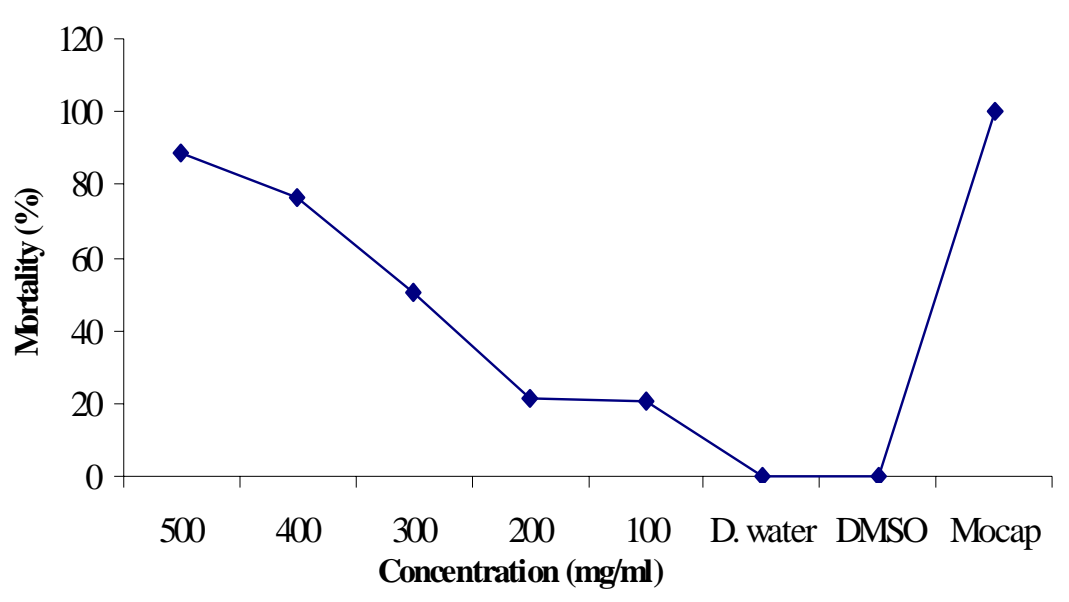

Figure 6. Mortality of nematode larvae immersed in ethyl acetate fractions fromPaecilomyces lilacinus culture

Using different solvent systems, 16 fractions were produced from the crude dried extract using vacuum liquid chromatography (VLC) (Figure 7). Based on the Rf values as shown in thin layer chromatography (TLC) plates, some fractions were combined resulting in 6 fractions (Figure 8). Bioassay against nematode revealed that fraction 3 (fractions 5, 6, and 7) gave 39 percent mortality. The compound is non polar based on its affinity to the solvent system used.

\section{Identification of the Compound by GC-MS}

The active fraction contains more than 20 compounds with 5 major ones $[4,6,7,14,19]$. (Table 1) The structure of the main compound [19] was partially identified as derivative of azulene containing two unsaturation points based on the fragmentation pattern in GC-MS (Figure 9). The main component has a molecular weight of 207 and looks like a derivative of globulol (Figure $10 \mathrm{~A}$ and B). However, other functional groups in the molecule would not likely be the same since double bonds are also detected. The limited amount of the fraction subjected to spectroscopic analysis 


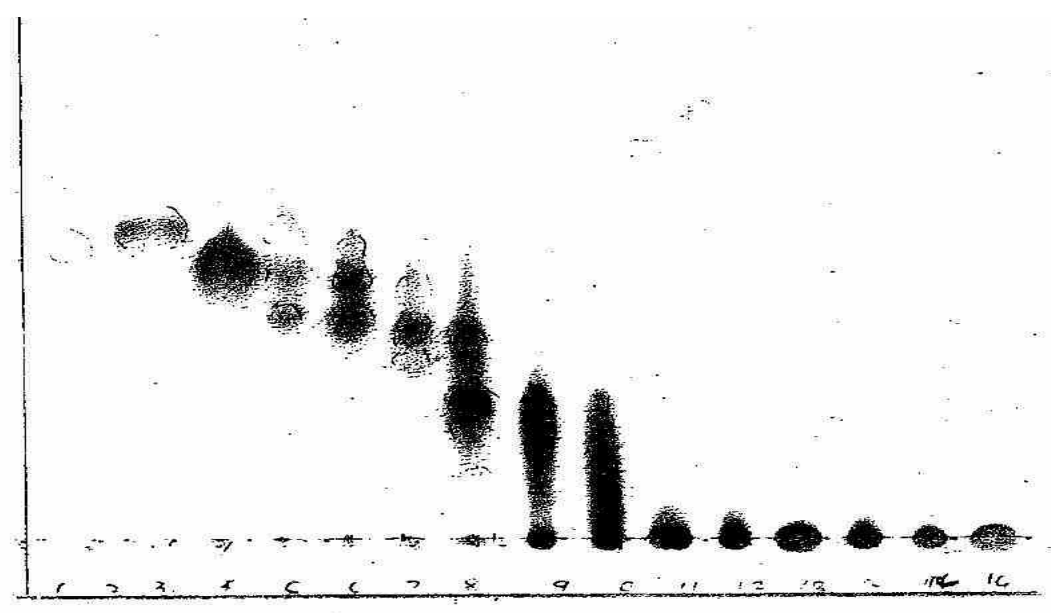

Figure 7. TLC profile of the 16 fractions from dried ethyl acetate extract of Paecilomyces lilacinus. Solvent system used for development is 1:1 ethyl acetate, hexane

does not warrant its purification to be able to do other analysis such as NMR spectroscopy for structure elucidation and complete compound identification.

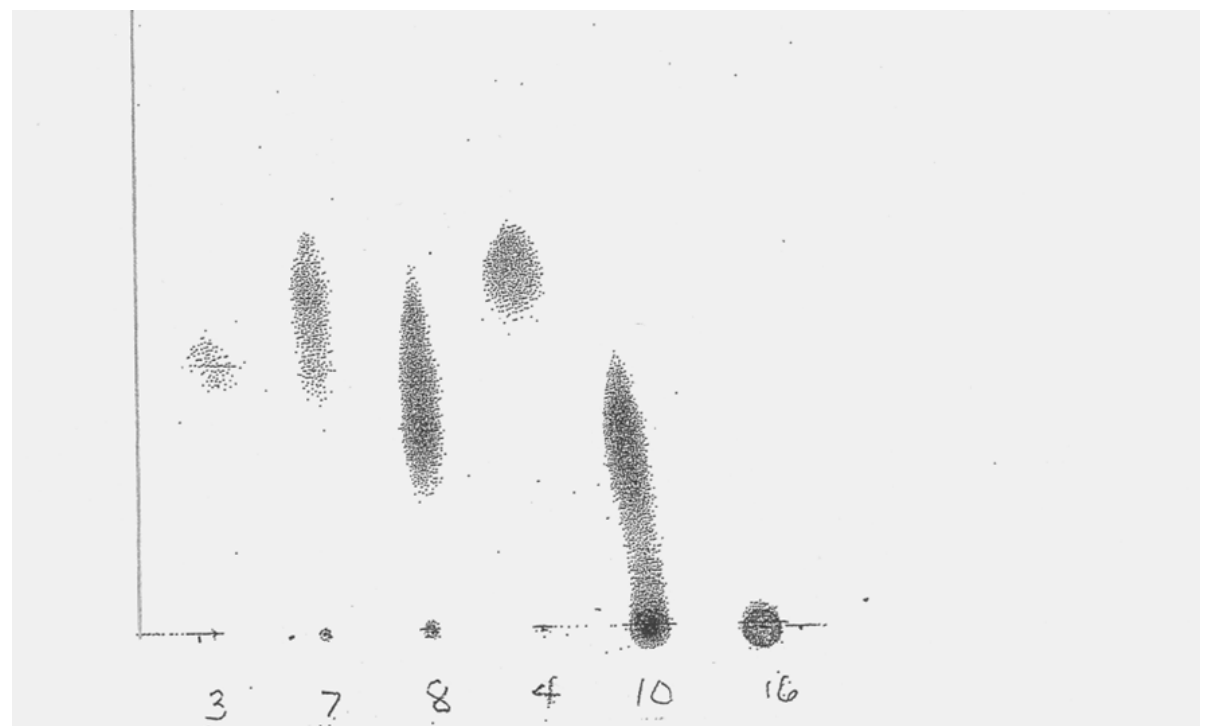

Figure 8. TLC profile of the combined fractions from dried ethyl acetate extract of Paecilomyces lilacinus. Solvent system used for development is 1:1 ethyl acetate, hexane 
Table 1. Major compounds present in the active fraction of the ethyl acetate extract from Paecilomyces lilacinus.

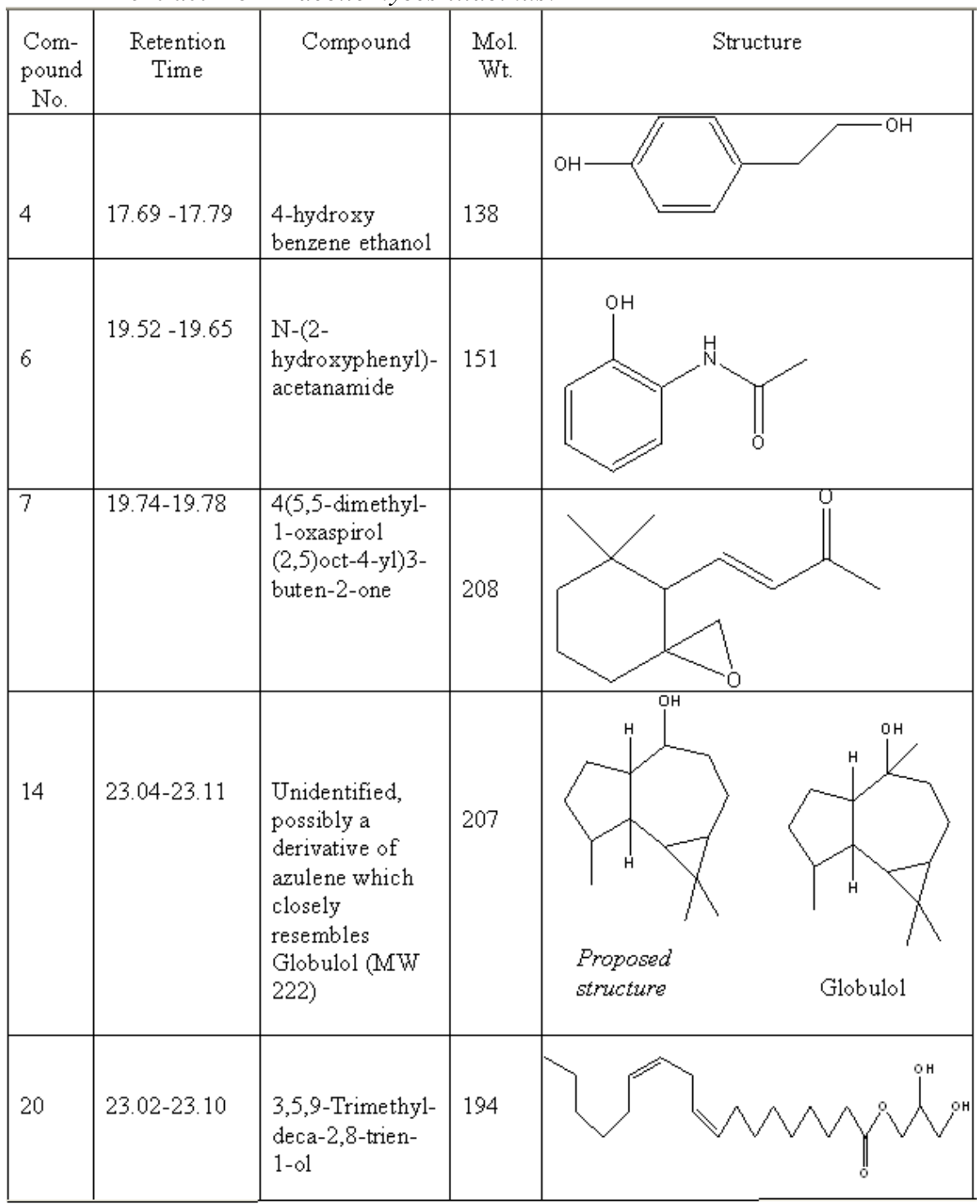




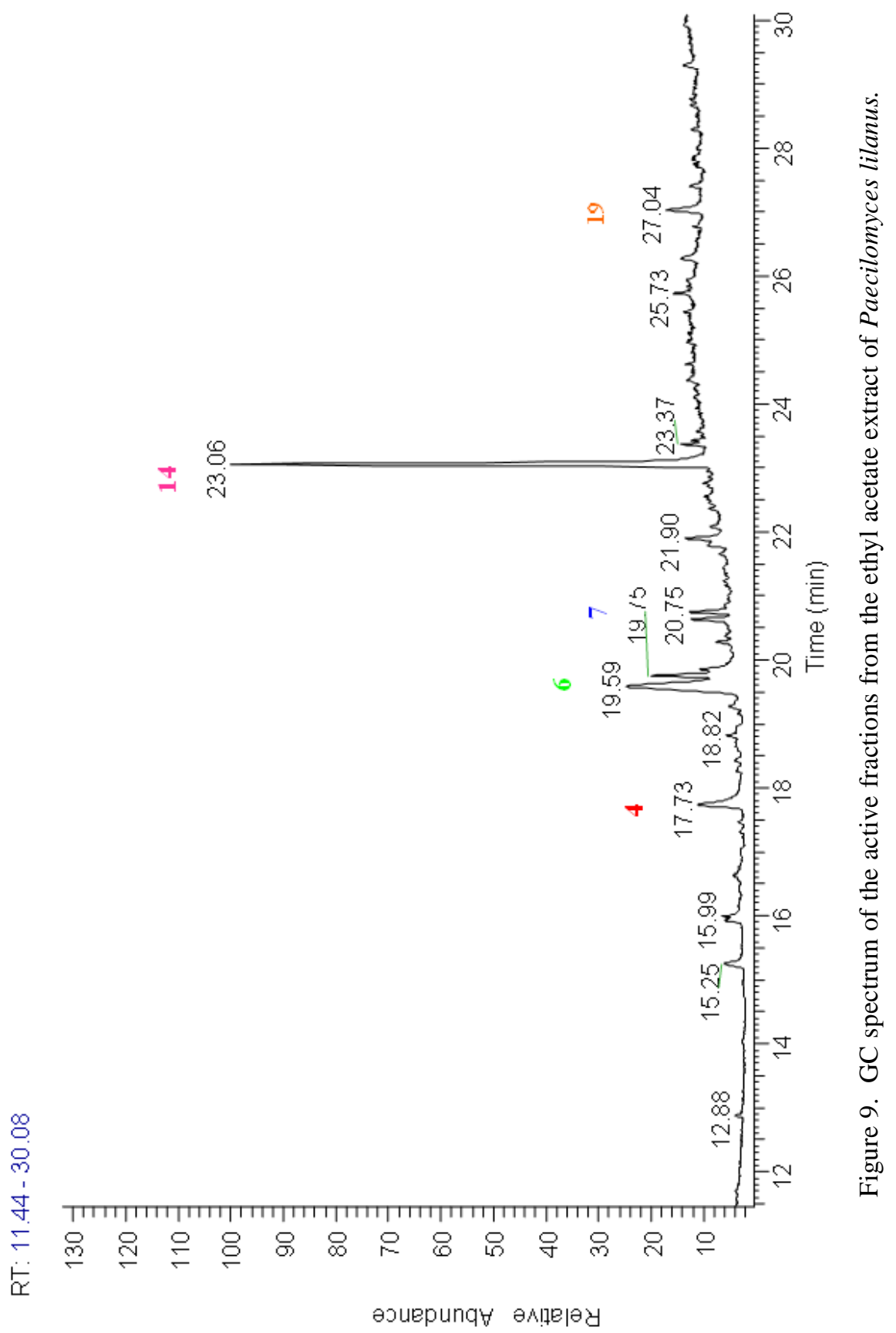




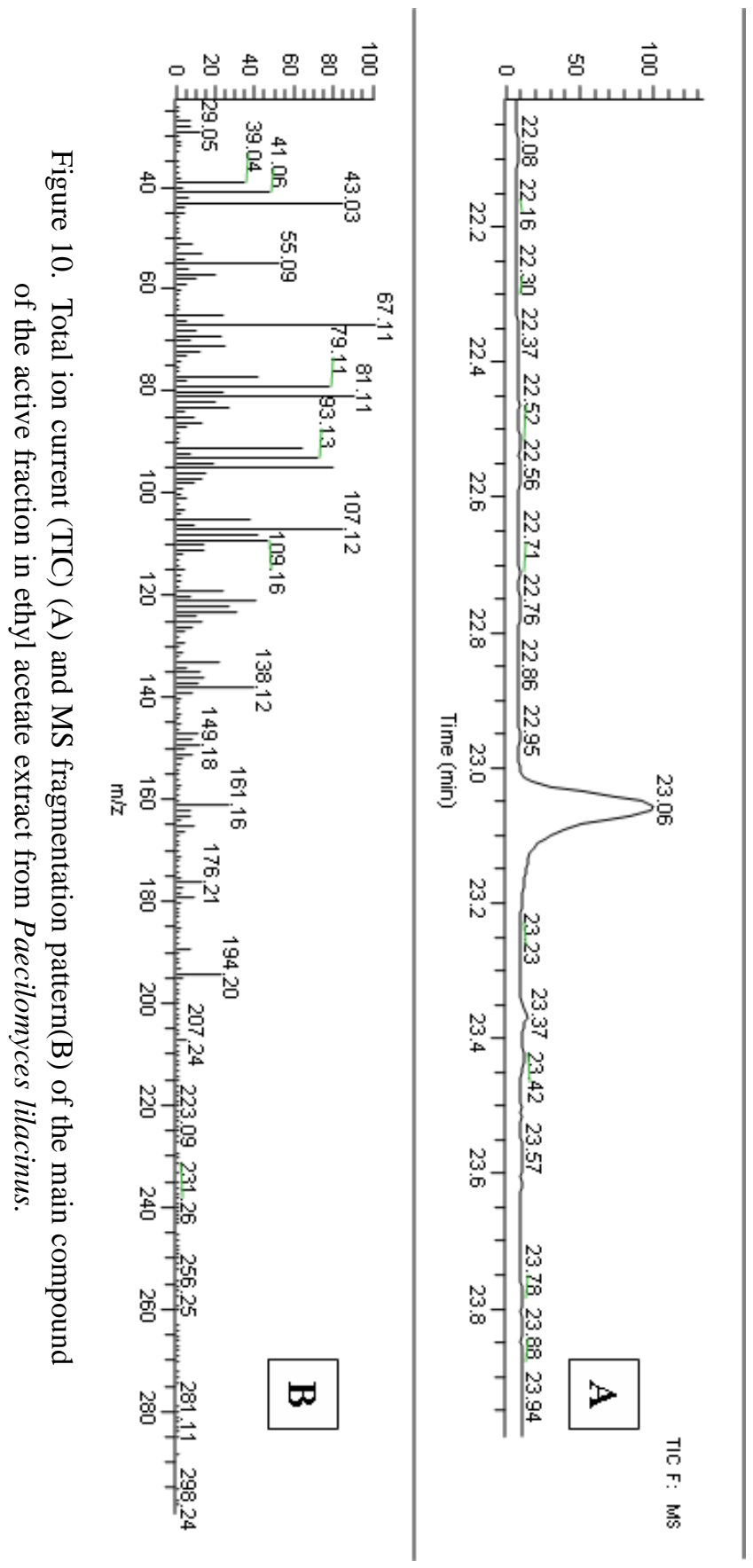




\section{CONCLUSION AND RECOMMENDATION}

Paecilomyces lilacinus produces metabolites that are nematoxic against the larvae of the rice root-knot nematode, Meloidogyne graminicola as exemplified by $100 \%$ mortality of larvae even at $50 \%$ concentration of the culture filtrate. Extraction of the metabolites with ethyl acetate gave $88.32 \%$ mortality at concentration of $500 \mathrm{mg} / \mathrm{ml}$. Fractionation of the dried extract yielded 16 fractions with subfraction 3 (fractions 5, 6, and 7) as the most toxic giving 39\% larval mortality.

It can be concluded that based on the available data, metabolites are produced by $P$. lilacinus which are nematoxic against the rice root-knot nematode, M. graminicola. The metabolites are non polar. Furthermore, the active fraction contains more than 20 compounds with 5 major ones. The structure of the main compound [19] was partially identified as derivative of azulene containing two unsaturation points. The limited amount of the fraction subjected to spectroscopic analysis allowed us to do partial identification since materials are not enough to proceed purification for other analysis such as NMR spectroscopy for structure elucidation and complete compound identification.

\section{ACKNOWLEDGMENT}

The authors would like to thank the Natural Science Resource Institute (NSRI), U.P. Diliman, Quezon City through DA-BAR for funding this research, the Institute of Organic Chemistry, Hohenheim University, Stuttgart, Germany and the Department of Pest Management, College of Agriculture, Visayas State University, Visca, Baybay City, Leyte.

\section{REFERENCES}

BARSALOTE, E. B. and R. M. GAPASIN. 1995. Pathogenicity of the root-knot nematode (Meloidogyne graminicola) on upland rice. Philipp. Phytopathol. 31:95-102. 
BRIDGE, J., and S. L J. PAGE 1982. The rice root-knot nematode, Meloidogyne graminicola, on deep-water rice (Oryza sativa subsp. Indica). Revue de Nematologie 5:225-232.

BARRON, G. L. 1977. The nematode-destroying fungi. Guelph, Ontario: Canadian Biological Publications. pp.94-99.

CAYROL, J. C., C. DJIAN, and L. PIJAOWSKI. 1989. Study of the nematocidal properties of the culture filtrate of the nematophagous fungus Paecilomyces lilacinus. Reveu Nematol. 12:331-336.

DAHIYA, J. S. and D. P. SINGH. 1985. Inhibitory effects of Aspergillus niger culture filtrate on mortality and hatching of larvae of Meloidogyne sp. Plant and Soil 86:145-146.

DAVIDE, R. G. 1972. Nematodes of the Philippine Crops and their Control. National Science Development Board, Manila. 34pp.

DAVIDE, R. G. 1987. Biological control of nematode using Paecilomyces lilacinus in the Philippines. Phil. Phytopathol. 23:18-21.

DAVIDE, R. G. and R. A. ZORILLA. 1987. On-farm trials of a fungus, Paecilomyces lilacinus against potato cyst nematode and other species in Benguet Province. Phil. Phytopathol. 23:1-7.

DECHECHI GOMES CARNEIRO, R. 1986. Etude des possibilities d'utilization du champignon nematophage Paecilomyces lilacinus (Thom.) Samson, 1974, comme agent de lutte biologique contre Meloidogyne arenaria (Neal, 1989), Chitwood, 1949. These Parasitol., Univ. Sci Techn. Languedoc, Montpellier, 119 p.

DELA PIZA, R. M. 2003. Nematicidal activity of Paecilomyces lilacinus (Thom) Samson culture filtrate against root-knot nematode, Meloidogyne incognita (Kofoid and White) Chitwoood. B.S. Thesis, Leyte State University. 45 p. 
DIAMONDE, M. 1981. Root-knot nematodes on upland rice (Oryza sativa and $O$. glaberrina) and cassava (Manihot esculenta) in Ivory Coast p.27. In: Proceedings Third IMP Res.Plann. Conf. On Root-Knot Nematode Meloidogyne spp. Regions IV and V, No. 16-20, 1981. Int. Inst. Trop. Agric. Ibadan, Nigeria. 275 p.

GALANO, C. D., R. M. GAPASIN, and J. L. LIM. 1996. Efficacy of Paecilomyces lilacinus isolates for the control of root-knot nematode [Meloidogyne incognita (Kofoid and White) Chitwood] in sweetpotato. Ann. Trop. Res. 18:12-23.

GAPASIN, R. M. 1996. Evaluation of Paecilomyces lilacinus (Thom) Samson for the control of Pratylenchus sp. in corn. Biocontrol 1:41-49.

GENERELAO, L. C. and R. G. DAVIDE. 1986. Biological control of Radopholus similis on banana with three nematophagus fungi. Phil. Phytopathol. 22:36-41.

HOLLIS, J. P. and S. KEOBOONRUENG. 1984. Nematode parasites of rice. pp.95-146. In: Plant Insect Nematodes (W. R. Nickle, ed). Marcel Dekker Inc., New York. 647 p.

MANKAU, R. 1980. Biocontrol: Fungi as nematode control agents. Journal of Nematology 12:244-252.

MORGAN-JONES, G., J. F. WHITE, and R. ROGRIGUEZ-KABANA. 1983. Phytonematode pathology: Ultrastructural studies. 1. Parasitism of Meloidogyne arenaria eggs and larvae by Verticillium chlamydosporium. Nematropica 13:245-260.

MORGAN-JONES, G., J. F. WHITE and R. RODRIGUEZ-KABANA. 1984. Phytonematode pathology: Phytonematode pathology Ultrastructural studies. 2. Parasitism of Meloidogyne arenaria eggs and larvae by Paecilomyces lilacinus. ROY, A. K. 1982. Survival 
of Meloidogyne graminicola eggs under different moisture conditions in vitro. Nematologia Mediterranea 10: 221-222. Nematropica 14:57-71.

MORGAN-JONES, G. and R. RODRIGUEZ-KABANA. 1985. Phytonematode pathology: Fungal modes of action. A perspective. Nematropica 15:107-114.

MORGAN-JONES, G., R. RODRIGUEZ-KABANA, and P. JATALA. 1986. Fungi associated with cysts of potato cyst nematodes in Peru. Nematropica 16:21-31.

PARK, J, G. R. STIRLING and K. SIVASITHAMPARAM. 1998. Variation in the nematicidal activities of Australian isolates of Paecilomyces lilacinus. ICPP98 Paper No. 2.10.6. 1 page.

RAO, Y. S. and H. BISWAS. 1973. Evaluation of yield loss in rice due to the root-knot nematode Meloidogyne incognita. Indian Journal Nematology 3:74.

ROY, A. K. 1982. Survival of Meloidogyne graminicola eggs under different moisture conditions in vitro. Nematologia Mediterranea 10:221-222.

RODRIGUEZ-KABANA, R., G. MORGAN-JONES, G. GODOY, and B. O. GINTIS. 1984. Effectiveness of species of Gliocladium, Paecilomyces and Verticillium for control of Meloidogyne arenaria in field soil. Nematropica 14:155-170.

SASSER, J. N. 1979. Pathogenicity, host range and variability in Meloidogyne species In: Root-knot nematodes (Meloidogyne species) Systematics, Biology and Control (T. Lamberti and D. E. Taylor, eds). Academic Press, London, NewYork, San Francisco. pp. 257-268. 
SASSER, J. N. and D. W. FRECKMAN. 1987. A world perspective on nematology: The Role of the Society. pp. 7-14. In: Vistas on Nematology (J. A. Veech and D. W. Dickson, ed). Society of Nematologists. Hyattsville, Maryland. 211 p.

SOOMRO, M. H. 1989. Survival of rice root-knot nematode juveniles in moist soil. International Rice Research Newsletter 14:35.

SORIANO, I. R. S., and J. C. PROT. 1992. Plant parasitic nematodes associated with irrigated rice in the Philippines. Phil. J. Crop Sci. 17:8-28. 